Resumo

O trabalho almeja fazer uma contribuição aos traços teoréticos do ensino universitário, tomando em conta os efeitos que permite a teoria psicanalitica. Especialmente, relaciona-se a noção de "desejo do ensinante", estabelecida por Lacan, com a natureza básica deste tipo de ensino. O texto pretende mostrar a importancia do "saber em falta" na discussão sobre a tradição universitária de ensino e suas diferenças com a tradição da teoria de ensino da educação moderna. Além do mais, incluise uma discussão sobre o estatuto da relação ciência-ensino, principalmente em referência ao "cientificismo" psicanalítico. Descrirores: ensino superior; psicanálise; professores universitários.

\section{PARA ALÉM DOS "ENCAIXAMENTOS": A NOÇÃO DE ENSINO UNIVERSITÁRIO AFETADA PELA TEORIA PSICANALÍTICA}

\section{Luis Ernesto Behares}

\section{A Universidade, o ensino e Jacques Lacan}<smiles>[CH]1C=CC1</smiles>
m 1962, Jacques Lacan (2006d, p. 187) se perguntava a respeito do "desejo do ensinante", e concluía que se fazer essa pergunta é já assumir que há ensino. Aquela colocação de Lacan parece reduzir a questão do ensino às possibilidades do dizer sobre o "desejo do ensinante", como se esse desejo fosse o eixo nocional da reflexão psicanalítica sobre o ensino. Em termos estritos, essa "redução", consequente com o arcabouço da sua versão das teorias do sujeito e do saber/conhecimento, permite a Lacan

Professor Titular e Diretor do Departamento de Enseñanza y Aprendizaje, Instituto de Educación, Universidad de la República, Montevideo - Uruguay. 
afastar a noção de ensino das "práticas" e das "intervenções" no desenvolvimento. Convencionalmente, um "professor" é uma escrita institucional (alguém que realiza práticas profissionais reconhecidas como "ensino"), mas também um espaço de atribuição de "inclinações subjetivas" de seu eu consciente (as vontades ou apetências que levam alguém a se constituir como "professor"). Sem dúvidas, determinações deste tipo são consideradas evidentes; são apresentadas como politicamente corretas, já que tem amplas "repercussões sociais", e são muito apreciadas pelos ideólogos das "identidades docentes". Porém, para além das mesmices pedagógicas, um "professor" é bastante menos que tudo isso; considerado pelo minimum, é um sujeito "ensinante", um efeito na fórmula $\$<>$ a do desejo diante da perene falta de saber que insiste em não se inscrever.

A afirmação de que o ensinante se define em ocasião da falta de saber (ou, melhor, da falta de um pretenso saber), que temos explorado com bastante atenção em Behares (2010), nos permite situá-lo em sua dimensão desejante, toda vez que o ensino venha a ser caracterizado entre o gozo utilitário da coisa reificada no imaginário estável e o desejo que nasce e vive da falta dela no Outro da incompletude. O desejo e o gozo do ensinante não existem fora dessa polarização.

Um professor não é muito mais do que o efeito dos seus ensinamentos, "se define então como aquele que ensina sobre os ensinos", afirma Lacan (2006d, p. 189). Como corolário, Lacan completa sua análise com uma sequência discursiva que poderia merecer o rótulo de "conselho aos professores":

No es inútil percatarse de que el profesor se define entonces como aquel que enseña sobre las enseñanzas. Dicho de otra manera, hace un recorte en las enseñanzas. Si esta verdad fuese mejor conocida -que se trata de algo análogo al collage-, ello permitiría a los profesores poner un poco más de arte en el asunto, de que el collage, con el sentido que ha adquirido en la obra de arte, nos muestra la vía. Si hicieran un collage preocupándose menos de que todo encajara, de un modo menos temperado, tendrían alguna oportunidad de alcanzar el mismo resultado al que apunta el collage, o sea, evocar la falta que constituye todo el valor de la propia obra figurativa, por supuesto cuando es una obra lograda. Y por esta vía llegarían a alcanzar, pues, el efecto propio de lo que es precisamente una enseñanza (Lacan, 2006d, pp. 187-188, grifo nosso).

É retrospectivamente evidente que, se os resumos aqui são os parâmetros constitutivos de uma possível "noção" lacaniana de en- 
sino, ou de uma aproximação a ela, o "ensino" do próprio Lacan seria um excelente exemplo de seus limites. Com efeito, Lacan ensinou durante décadas - o seu Seminaire é a prova, apesar da dificuldade das transcrições desde sua oralidade constitutiva, das querelas de "autoridade" de seus herdeiros e discípulos, e de algumas tendências a tomar o conjunto dos seus ensinamentos orais como uma coleção de "livros" ou de "escritas". Como tem argumentado extensamente Milner (1995/1996, pp. 13-34), os materiais do Seminaire constituem ou se apresentam como um "tipo de obra”, mas são dizeres que tinham na sua proferência as marcas vivas de uma "eficácia", a mesma que foi necessário perder para que virasse "Obra".

Não seria muito difícil, porém tedioso, individualizar, isolar, e fazer um corpus de todas as sequências em que Lacan falou sobre o seu "ensino" ou "ensinamento" ao longo do Seminaire. De fato, é claramente evidente que Lacan tinha como referente básico de ensino o que ele mesmo costumava fazer, que passou a denominar-se "o estilo de Lacan", e também "o meio dizer". Eis, entre outros fatores não menos importantes, uma das causas da crise e ruptura entre Lacan e a Universidade: a questão do ensino.

O 25 de junho de 1969 Lacan (1968-1969/2008) anunciou que o Seminaire não poderia mais funcionar no prédio da École Normal Superieur, 
como tinha sido habitual nos últimos cinco anos. $\mathrm{Na}$ nota em que se comunicou essa que Lacan considerou uma "expulsão", o Diretor Robert Flacelière indicava:

La reorganización de los estudios en la Escuela, que es una consecuencia de la reforma general de las universidades y de la reciente ley de orientación de la enseñanza superior, así como el desarrollo de las enseñanzas en varias disciplinas, nos harían imposible a partir de octubre de 1969 el préstamo del aula Dussane o de cualquier otra aula de la Escuela para su uso (citada em Lacan, 1968-1969/ 2008, p. 366, grifo nosso).

A referência de Flacelière à "reforma geral das universidades", ocorrida após os fatos de maio-junho de 1968, põe uma nota contextualizadora importante, porque a lei de 1969, apesar de ter durado pouco, teve que ser modificada em 1972, iniciando-se o caminho em direção a um ideal de ensino "eficiente", direcionado ao profissional, formalmente regulado pela avaliação de resultados, que deu mais importância aos efeitos práticos do saber que à indagação e o "pensamento original".

Após a clausura, aquele mesmo dia, do curso 1968-1969, houve a ocupação da moradia oficial de Flacelière por parte dos ouvintes do Seminaire, e nos dias seguintes um vai e vem de cartas do Diretor da École e de Lacan, ríspidas e carregadas de agressividade verbal. Em uma delas, Fracelière define o ensino de Lacan como "mundano, incompreensível para qualquer 
um normalmente constituído, e não científico". Em um texto daqueles dias em apoio a Lacan, um grupo de oitenta e cinco pessoas declarava que seria extremadamente lamentável e inquietante que o Doutor Lacan fosse privado de um lugar para seu ensino universitário (dados dos Anexos a Lacan 1968-1969/2008, pp. 386389).

O Seminaire de 1969-1970 iniciase em 26 de novembro de 1969 na Faculdade de Direito, ainda com os rescaldos do fogo das batalhas de junho na Escola Normal Superior. Era um âmbito universitário diferente, sem lugar a dúvidas, mas, como o próprio Lacan anunciou, já na primeira das "aulas", "lições" ou "conferências" (que são os três nomes que utiliza para se referir ao que ele fazia ali), mais um dos seus "desplazamentos" (Lacan, 1969-1970/1992, p. 9). A relação entre o ensino de Lacan (seus conteúdos, seus objetivos, sua forma) e a Universidade, adquirem assim, por via de um insight dele próprio, um sentido profundamente deslocado, ou seja: fora do lugar, ou em relação metonímica. Seu ensino estava fora de lugar em Sainte-Anne, espaço do ensino médico que ele não iria oferecer, mas também fora da Escola Normal Superior, lugar de outros ensinos: mesmo se os normalistas são os que sabem muito bem que não é preciso saber alguma coisa para ensiná-la (de acordo com o aforismo do próprio Lacan, 1969-1970/1992, p. 25), o seu ideal de ensino aproximava-se triste- 
mente ao dos anagnostas (escravos romanos que eram obrigados a ler em voz alta durante os banquetes).

Não estou interessado nem na anedota, muito menos na "fofoca" acadêmicas, até pelo simples fato de que referem a circunstâncias acontecidas faz mais de quatro décadas, em uma França e uma universidade francesa que mudaram bastante no decorrer dos anos. Incluo aqui a lembrança daqueles fatos, porque acredito que neles podemos situar algumas claves complementares ao respeito das versões possíveis da noção de ensino universitário. Só pelo fato de falar em "ensino", de utilizar esse nome comum, estamos implicando uma dimensão discursiva complexa, que pode cair facilmente nas nuances da "professoridade" corriqueira, mais ou menos interessantes, porém “inmateriais”. Mesmo assim, se escutamos materialmente o que esse discurso acarreta, é possível identificar os nós estruturais que o determinariam, ou, em outros termos, sua composição teórica. As necessárias distâncias entre o anedotário e a teoria parecem, não obstante, receber atualmente pouca autorização no campo do ensino, devido, talvez, às notórias tendências pragmatistas que acabaram por ser uma das suas características mais preocupantes.

\section{A questão teórica do ensino universitário}

A teoria do ensino, iniciada nas discussões entre os "filósofos" e os "sofistas" durante os séculos V e IV a.C., e sempre reformulada ao longo dos séculos até chegar a suas construções próprias do século XIX, precede historicamente à psicanálise. Quando Freud começou a construir um ponto de vista novo, que afetaria posteriormente todo o campo humanístico, já se deparava com aquela tradição ancestral inseparável, entre outras, da filosofia, da teoria do conhecimento, da epistemologia, e das outras discursividades referidas ao humano. Além do mais, a construção histórica da psicanálise é temporalmente paralela à das disciplinas que no século XX abrangeram a questão do ensino: a "pedagogia", a didática, a psicologia da educação, a psicopedagogia, a teoria curricular etc. Por conseguinte, é importante que prestemos atenção aos parâmetros que foram possíveis para definir "ensino" e "ensino univérsitario" no discurso inerente à teoria do ensino. 
$\mathrm{Na}$ teoria do ensino as questões tipicamente modernas do ensino universitário ou ensino superior apresentam enormes dificuldades conceituais. Embora tenham nascido no contexto medieval, as universidades só adquirem representação consistente sob as influências da modernidade. Nesse contexto, desde o século XVII, a teoria do ensino passou a estar constituída progressivamente como teoria das intervenções no desenvolvimento do aluno, em versões sucessivas que atracaram finalmente, no início do século XX, na centralidade da aprendizagem e sua indistinção com as teorias da educação ou "pedagógicas" (no sentido etimológico primitivo: aquilo que se faz para encaminhar as crianças). Por óbvias razões, o que poderia ser feito nas universidades com o nome de ensino ficou majoritariamente por fora desse projeto "pedagógico".

O que estamos chamando de "teoria do ensino" não pode ser identificado linearmente com uma teoria no sentido de sistema fechado e totalmente homogêneo de proposições para constituir um objeto (episteme), ou para instrumentalizar metodologicamente a abordagem de um fenômeno que, por esse procedimento, pode se tornar "simples". Trata-se, contrariamente, de um conjunto relativamente coerente de construções conceituais que pretendem descrever, explicar e, frequentemente, dar sentido teleológico a um fenômeno muito complexo que abrange diversas di- mensões estruturantes. Contudo, o campo de abrangência dessa teorização pode ser delimitado e considerado como uma "tradição discursiva", na que é normal se encontrar ao longo dos séculos de afetações oriundas de outros campos humanísticos. Em um trabalho recente (Behares, 2011), estabelecemos pelo menos quatro dimensões discursivas que formam parte imprescindível do campo teórico do ensino, porquanto referem à complexidade fenomênica dos seus "objetos": a) a dimensão epistêmica, b) a dimensão política, c) a dimensão de sujeito, e d) a dimensão de práticas.

A dimensão epistêmica tem sido sempre, com muito, a região central da teorização sobre o ensino. Quase poderíamos dizer que há ensino porque há saber ou conhecimento, e se não o houvesse não existiria nenhuma necessidade de que o termo "ensino" viesse a ser utilizado. A antiguidade tinha esta discussão como uma das essencialidades da reflexão sobre o ensino, por sua parte a modernidade, sob a forma do vínculo ciênciaensino, potencializou a atenção sobre os saberes que fazem parte dos processos do ensino. De fato, a existência de um campo pragmático, que se costuma chamar de "teoria e prática do curriculum" desde os anos de 1940, é um reconhecimento de que, para além da comunicação entre aluno e professor e das suas modulações (que corresponderiam à Didática), há no processo uma presença determinante do conhecimento, já como acu- 
mulação e conservação do conhecimento recebido, já como dispositivo heurístico de produção de conhecimento original.

A importância da dimensão políti$c a$, em grande parte, decorreu historicamente dos definidores epistêmicos do campo. Com efeito, os diversos projetos políticos, de maior ou menor envergadura, têm situado o ensino e seus sentidos em relação aos projetos filosóficos ou teológicos na antiguidade e na idade média, e científicos na modernidade. Nem a filosofia, nem a teologia, muito menos a ciência, são tarefas angélicas, mas humanas, e estiveram sempre regidas pelas materialidades históricas dos grupos e estruturas de poder caraterizáveis como políticas.

A dimensão de sujeito do campo teórico do ensino tem sua origem nessa necessária sujeição. Vizinhas constantes das concepções de ensino, as noções de sujeito formaram parte integrante de toda ou qualquer versão da teoria do ensino. As noções de sujeito, às vezes expressas em termos acadêmicos explícitos e outras vezes em termos do "sentido comum", colocaram em ação "sujeitos do ensino" (os "ensinantes") e "sujeitos de aprendizagem" (os "aprendizes"), e criaram conceitualmente as bases para configurar as relações descritíveis, explicáveis ou desejadas entre ambos (ou "vínculo de ensino"). A profunda psicologização do campo teórico do ensino, ocorrida no século $\mathrm{XX}$, determinou que as confi- 
gurações dessa dimensão fossem transferidas para a teoria da aprendizagem, nas suas variadas formas, apagando suas complexidades.

Os afazeres do ensino, que agrupamos na dimensão de práticas, constituem para a modernidade póscomeniana o cenário da Didática, que alberga o conjunto das propostas tecnológicas referidas ao "como ensinar", das "metodologias", das definições sobre o "bom" e o "mau" ensino, dos projetos ou programas gerais ou específicos a seguir no ensino, e outras construções não menos teleológicas e geralmente prescritivas. Nelas é sempre possível entrever a presença determinante das outras três dimensões, mesmo se latentes.

O século XIX consagrou a dominância da consideração centralmente política do ensino. Com efeito, a modernidade submergiu o ensino no campo do que se costuma chamar educação, de indubitável e explícita condição política, e fez uma inclusão euleriana (o campo do ensino é um círculo menor incluso no círculo maior da educação), se assegurando assim o controle dos cidadãos, (principalmente as crianças e os jovens), e sua sujeição social pelo conhecimento. Os ideais modernos de educação "universal" foram fortemente atrelados aos ideais de progresso social, nos quais as versões da ciência unificada às tecnologias (físicas, instrumentais, mas também sociais) ocuparam progressivamente o espaço central. Ensinar, neste contexto, é um compo- 
nente complementar, embora importante, na formação de sujeitos sociais adequados para viver no mundo industrial e das democracias burguesas, e o ensino contribui para assegurar o stock de conhecimentos e utensílios necessários para uma inserção produtiva de cada sujeito. Simultaneamente, os treinamentos para além da transmissão de conhecimentos, ou seja, aqueles que têm a ver com os comportamentos aceitáveis, valores e identidades, geram o espaço próprio da educação como esforço de maior amplitude, no qual o ensino está compreendido como mais um instrumento.

A preocupação acadêmica sistemática pelo desenvolvimento de crianças e adolescentes desde os inícios do século XX e a posterior ênfase nos achados dessa indagação pelos modelos educacionais, permitiram a "descoberta" na psicologia experimental e a inclusão nas teorias educacionais da noção essencialmente comportamentalista da aprendizagem. Os "educadores" e as teorias pedagógicas fizeram logo mais possível completar o arcabouço psicologista das teorias do ensino: nas práticas educacionais o aluno passou a ocupar o centro de atenção e o ensino concebeu-se como mais um aspeto da intervenção técnica no desenvolvimento psicológico "integrado" dos alunos. O saber, sob a forma de conhecimento-conteúdo, foi marginalizado e reduzido no processo. Há, claramente, uma relação entre as ênfases postas no ensino como ato de comunicação e "formação de sujeitos de conhecimento" e o "declínio dos saberes": o saber vira conteúdo e mercadoria, e perde sua mais inquietante dimensão de "pensamento". O ingresso destes arranjos conceitualizadores do ensino na vida das universidades a puseram em mãos das abordagens pedagógicas (ou deveríamos dizer "pedagogistas", com todos os espantos possíveis e os mais alarmados ênfases pejorativos?), que implicaram a conseguinte postergação dos interesses epistêmicos. A pergunta de Voltolini (2010, p. 28) coloca a questão no patamar de uma perda angustiante: "Como a Universidade, originalmente lugar de altos estudos, estudos avançados possibilitados pelo uso potente da razão e da reflexão, teria se tornado um lugar de reprodução e fundamentalmente de 'consumo de conhecimentos'?"

\section{Freud, a "vulgata psicanalítica", o ensino e a Universidade}

Na vasta obra de Freud as questões do ensino e da universidade não ocupam quase nenhum espaço. Sobre o ensino, os possíveis aportes de Freud podem ser interpretados em relação ao seus depoimentos sobre o fenômeno do saber, do conbecimento e 
da educação. Em outro trabalho (Behares, 2007) temos vasculhado as possíveis bases para entender as afetações freudianas à teoria do ensino, com base na sua concepção das origens "pulsionais" ou "sexuais" do saber, a natureza pulsional de toda relação humana com o conhecimento representável (Freud, 1905/2003a, 1915/ 2003b, 1908/2003c e 1915/2003d) e as derivações que este ponto de vista acarreta em termos da teoria do ensino. São conhecidas, também, e muito bem analisadas (Lajonquière, 1999), as afirmações de Freud referidas ao caráter impossível da educação (Freud, 1925/ 2003f, 1937/2004a): na medida em que há uma dimensão constitutiva do sujeito que escapa radicalmente a todo efeito da ordem do controle e da direção do outro psicológico, que Freud observa emparelhada às impossibilidades da "cura" ou "término da análise" para a própria psicanálise. De fato, e como assunto não muito bem explorado, subsistiria a questão de se as possibilidades do ensino, na sua precariedade, são as mesmas que as da educação, toda vez que forma parte das interioridades-exterioridades da relação do sujeito com o saber-conhecimento.

Já a questão da universidade parece ser mais alheia aos interesses de Freud. Devemos lembrar que ele próprio teve uma relação muito insegura com essas instituições: com efeito, esteve "dentro delas" só no seu período de aluno de medicina e pouco mais, num período conflitivo para ele. Freud permaneceu como aluno na Universidade de Viena entre 1873 e 1881, tempo considerado excessivo para uma graduação "normal". Entre 1876 e 1882 foi assistente de Brücke no Instituto de Fisiologia dessa Universidade, contexto no qual conheceu a seu colega e parceiro J. Breuer. Trabalhou também no Centro de Pesquisa do Hospital Geral de Viena (que tinha caráter universitário) entre 1883 e 1885 com T. Meynert, e em 1884 publicou o seu texto sobre a coca, que lhe criou uma reputação acadêmica controvertida. Embora tivesse ao longo da sua vida "contatos" esporádicos com universidades, e algum título de "Doutor Honoris Causa", permaneceu sempre por fora delas (Jones, 1961/ 2003, pp. 57-105).

Só em um breve texto (Freud, 1918/2003e), preparado para um congresso psicanalítico em Budapeste (Hungria), e publicado por Ferenczi em 1919 em húngaro, Freud expressou suas opiniões sobre as relações da psicanálise com as universidades. A versão alemã do texto não é conhecida, e foi redescoberto em 1955 por psicanalistas argentinos, que o publicaram em Buenos Aires em tradução 
ao espanhol. É bom lembrar que em 1919 a psicanálise foi incorporada como disciplina nos estudos médicos na Universidade de Budapeste (com Ferenczi como professor, já sob um governo comunista). Provavelmente, esta é uma das primeiras presenças formais da Psicanálise nas universidades junto com as incorporações estadunidenses. $\mathrm{O}$ assunto é tratado por Freud naquele texto em duas direções: a da psicanálise e a das universidades. Para a psicanálise, e principalmente para a formação dos analistas, a universidade não parece oferecer outros benefícios que os decorrentes do generalizado aporte de cultura, já que a própria análise e a bibliografia psicanalítica, junto com as associações de analistas, parecem ser suficientes. Para as universidades, o contato delas com a psicanálise resulta importante para a formação dos médicos (porque a psicanálise permitiria ir para além do puro organicismo e abranger os fatores psicossomáticos), principalmente dos psiquiatras (que seriam beneficiados com um complemento "profundo" em sua formação psicológica) e dos "homens de ciência em geral".

Em relação a essa última aportação possível, Freud escreveu posteriormente:

$\mathrm{Al}$ investigar los procesos psíquicos y las funciones mentales, el psicoanálisis se ajusta a un método particular, cuya aplicación en modo alguno está limitado al campo de las funciones psíquicas patológicas, sino que también concierne a la resolución de proble- mas artísticos, filosóficos o religiosos, suministrando en tal sentido múltiples enfoques nuevos y revelaciones de importancia para la historia de la literatura, la mitología, la historia de las culturas y la filosofía de las religiones (Freud, 1926/2004b, p. 171).

Mesmo assim, como assinala Kachinovky (2010), Freud não aceitava a transformação da psicanálise em uma cosmovisão ou um panóptico de caráter geral hermenêutico, e ficou por fora das "transdisciplinariedades" que outros analistas (como Jung, por exemplo) levaram adiante.

Ao chamar a atenção sobre "outros influxos" da psicanálise nas práticas do conhecimento existentes nas universidades, Freud reconheceu a existência da teoria psicanalítica para além da prática analítica, e a apresentou como uma contribuição a ciência em geral. "Naturalmente - disse (Freud, 1918/2003e, p. 171) - su enseñanza sólo podrá tener carácter dogmático-crítico, por medio de clases teóricas". Em 1926, Freud expressou da psicanálise: "Como 'psicología de lo profundo', doctrina de lo inconsciente anímico, puede pasar a ser indispensable para todas las ciencias que se ocupan de la historia genética de la cultura humana y de sus grandes instituciones, como el arte, la religión y el régimen social" (Freud, 1926/2004b, p. 232). Não obstante, e embora reconheça a importância da psicanálise na sua afetação mútua com outros saberes que ocupam a cena universitária, sobre os 
"modos de ensinar" nas universidades ou sobre a natureza desse ensino Freud não disse muito mais.

Em decorrência com as ideias de Freud, as relações inclusivo-exclusivas entre a psicanálise e as universidades adotaram as mais variadas formas na "vulgata", termo pelo qual entendemos, em alusão a versão católica da Bíblia, as construções e interpretações normais geradas pela comunidade psicanalítica com posterioridade a Freud. Em algumas tradições, a psicanálise ocupou um lugar mais ou menos exclusivo nas universidades, em outras ficou inevitavelmente por fora, em outras foi fagocitada pelas formações médicoterapêuticas da psiquiatria ou da psicologia, em outras fusionou-se com a psicologia para criar os efeitos próprios das chamadas "psicologia psicanalítica" ou "psicoterapias psicanalíticas". Com respeito a sua influência em outras ciências, para além das práticas de saúde, não pode se duvidar de seu influxo, caracterizado em muitos casos como uma ação completiva no nível das interpretações em diversos campos teóricos. Em matéria de ensino, em geral nos deparamos com complementos psicopatológicos de origem psicanalítica quando se trata de "dificuldades de aprendizagem", campo de extensa aplicação nas bordas do ensino básico.

Fernández (2006) mostra como a questão da criança, difícil de ser representada em termos da teoria psicanalítica, aparece nos trabalhos e dis- 
cussões de várias analistas (claramente em Anna Freud), ligada a versões pedagógicas e de desenvolvimento, alheias às construções freudianas, e potencialisadoras de uma redução da clínica a suas práticas psicológicas. Muitas dessas foram, como sabemos, a grama em que nasceram as psicopedagogias de "orientação psicanalítica”. Para além das práticas psicológicas, a psicanálise teve outras transliterações teóricas em direção ao campo educativo; porém, em termos teoréticos, essas se reduzem a algumas incorporações conceituais, tiradas de seu arcabouço teórico original, de acordo com o clima de ecletismo vago das "ciências da educação", como podem ser, apesar das suas diferenças, os casos de Rancière $(1995 / 2003)$ ou de Chevallard (1985/1998), para mencionar só dois dos exemplos melhor sucedidos e influentes.

\section{Lacan, o saber barrado, o ensino barrado}

Como já foi salientado ao começo deste texto, nos inícios dos anos de 1960, nos volumes numerados como 8, 9 e 10 do Seminaire (Lacan, 1960-1961/2003a, 19611962, 2006d), Lacan ocupou-se paralelamente da questão do ensino com as questões que deram nome a esses cursos: a transferência, a identificação e a angústia. Ao longo dessa década, Lacan tem insistido especificamente sobre o assunto, como demonstram suas conferências de 1967-1968 em diversos lugares (Lacan, 1967/2006a, 1967/2006c, 1968/2006b), reunidas por Miller em um livrinho em 2005. Em 1970, paralelamente ao curso 1969-1970, nomeado "O aveso da psicanálise" e numerado como 17 (Lacan, 1969-1970/1992), Lacan profere sua "Alocução sobre o ensino" no encerramento do congresso da Escola Freudiana de Paris em 1970 (Lacan, 1970/2003b). Porém, seu interesse na questão está documentado desde os primeiros cursos dos anos de 1950: com efeito, no primeiro deles, "Os escritos técnicos de Freud" (Lacan, 1953-1954/1993a), o ensino esta já presente em ocasião do texto "De Magistro" de Agostinho de Hipona (pp. 357-378), que é um texto fundamental do pensamento antigo e medieval sobre o ensino, embora que tenha sido lido sobretudo como um texto "linguístico" .

O nosso objetivo não pode ser o exaurimento das complexidades do pensamento de Lacan sobre o ensino nesse período, tarefa que consumiria longas páginas. A "complexidade" está presente em duas direções. Como é obvio, a primeira delas é o fato de Lacan se preocupar, como psicanalista, pelo ensino da psicanálise, ou o que desse poderia ser ensinado, ou o que há de possível em seu próprio ensinamento. Parte dessa discussão foi introduzida já no capítulo inicial deste texto. A segunda é a possibili- 
dade de achar uma contribuição de Lacan à teoria do ensino, com certeza existente milenarmente, e que sem lugar a dúvidas Lacan conhecia bastante bem, se lembramos suas referências a autores e construções teóricas e seu marcado interesse pelas questões do sujeito, do saber, da verdade e da ciência, que são as questões centrais da teoria do ensino. Podemos, portanto, almejar uma "síntese", se bem que saibamos que as sínteses são caminhos retorcidos quando tentam simplificar e unidirecionar um pensamento tão complementar como o de Lacan.

Um traço evidente do tratamento que Lacan faz da questão do ensino é a rejeição nominal do par ensinante-ensinado, que sempre inclui a aceitação tácita do par pedagógico educador-educando ou professor-aluno, correlativos a pares como médico-paciente e psicanalista-psicanalizado, todos eles no formato ativo-passivo, que remete à impossível relação significantesignificado, e à impossibilidade do ato sexual. Nesses pares aceita-se sem discussão que de todo ensino há um resultado linear na aprendizagem, "que dele [do ensino] resulte um saber", diz Lacan (2003b, p. 302) e acrescenta:

Dou a isso uma reflexão, balística, entendamna, ao me espantar de que a todo instante tenha parecido evidente que o ensino era a transmissão de um saber, tomando-se por horizonte o pêndulo que vai e vem entre aquele que ensina e o ensinado [l'enseignante l'enseigné, no original em francês]: a relação entre eles - por que não? - é o barco que convém, ao encontrar, na grande feira de nossa época, seu impulso, não mais disparatada do que a relação médico-paciente, por exemplo (Lacan, 2003b, p. 303, nosso grifo).

O "espanto" de Lacan perante essa construção própria da pedagogia, que implica a aceitação da comunicação transparente do saber correlativa à ação direta sobre o outro, é repetida por Lacan em múltiplas ocasiões. Sem dúvida, essa "suspeita" que desde seu arcabouço teórico (por sinal, não diferente ao de Freud neste aspecto) põe uma barra a todo pensamento pedagógico, o fez vituperar toda e qualquer posição pedagógica: "la profunda maldad de toda posición pedagógica” (Lacan, 2006d, p. 302). Porém, o despreço não é corriqueiro (como se fosse uma queixa benevolente, psicologizante ou "progressista" em prol dos "direitos das crianças"), mas tem como sustento a construção da noção de sujeito. Com efeito, as possibilidades de um ensino "à altura do sujeito", que introduz em uma das conferências da década de 1960 (Lacan 2006a), baseia-se na afirmação axial de que o sujeito (\$) é sempre barrado.

Na conferência que acabamos de citar no Centro Hospitalário del Vinatier (Lyon), Lacan se debruçou sobre a questão do ensino, em ocasião do seu ensinamento e da "Teoria da Psicanálise Didática" (embora pareça estranho, ele mesmo utilizou essa expressão). Ali introduziu algumas palavras que se aplicam, em nossa 
opinião, a toda e qualquer versão possível da Teoria do Ensino. Ao se referir à tão debatida teoria da psicanálise didática, expressou que essa deve ser reduzida à questão de "cómo hacer psicoanalistas que estén a la altura del sujeto" (Lacan 2006a, p. 61). Como argumentamos em outro trabalho (Behares, 2008), essa "definição" é extrapolável (como o texto de Lacan parece autorizar) a qualquer teoria do ensino, ainda que as relações do sujeito com a psicanálise e com o ensino sejam diferentes. De acordo com Lacan, na sua Conferência de Bordeaux em 1968 (Lacan, 2006b), o sujeito do seu aforismo é o sujeito de Freud (e, portanto, o sujeito da psicanálise), embora Freud não pareça ter incluído essa noção. Como sabemos, trata-se do sujeito barrado, que não vive por e para o imaginário do gozo, mas na dimensão do desejo no simbólico, que o mantém na implacável falta do Real. Daí o impossível pedagógico, e a possibilidade relativa do ensino, se por esse podemos entender um espaço para o desejo, e daí também a remissão da questão do ensino para a questão do desejo do ensinante que Lacan consegue fazer no curso sobre a angústia (Lacan, 2006d).

$\mathrm{O}$ argumento lacaniano no curso sobre $A$ angústia (Lacan, 2006d) é simples: após abandonar a hipótese de que o ensino é da ordem da transmissão de conhecimento, continuam a existir os ensinantes representados por seu desejo. Só essa evidência basta para dizer que bá ensino. A sujeição desse desejo ao saber e à linguagem são seus traços básicos. Por isso, o ensinante ensina "sobre seus ensinamentos", no "cerco dos signos" como salientava Agostinho (Agustín de Hipona, 359/1873), na sufocante rede do sentido que torna possível a existência do conhecimento. Mas, como é obvio, ali há sempre uma falha, mesmo considerando as melhores aparências de completude e encaixamento, há o furo que inclui inevitavelmente o desejo e o saber que não se identificam com a verdade, mas também não com o conhecimento. Pensar o ensino como desejo, portanto, coloca a questão da ciência e da psicanálise e suas possibilidades de saber e verdade.

\section{Ensino e "cientificismo"}

Como tem sido profusamente assinalado, há entre a psicanálise e a ciência uma relação, que chamaremos de "distribuição comple- 
mentar", em sentido metonímico ao trazer esse termo desde a teoria fonológica. A afirmação se constitui, em versões diferentes, em textos de vários analistas do pensamento de Freud e Lacan, como Alouch (1993/1994), Milner (1995/1996) e Pommier (2004/2005), entre outros. Costumase chamar a essa "distribuição" com o nome, talvez não muito conspícuo, de "cientificismo", e se distinguem dois: o cientificismo freudiano e o cientificismo lacaniano.

O "cientificismo" de Freud tem como genus proximus o modelo da biologia médica positivista, o de Lacan estaria relacionado com a física, as matemáticas e a linguística, ou seja as ciências "formais". Isto não significa que qualquer um dos dois tenha incluído a psicanálise nas particulares redes método-teoria dessas configurações científicas, mas que houve com elas um diálogo necessário. A noção de "inconsciente", no que tem de possível "objeto" para a ciência que levaria o nome de "Psicanálise", é um bom exemplo desse diálogo. Freud esteve nos seus primeiros trabalhos nas bordas de atribuir positividade biológica à sua descoberta, com o que deu alimento a vários de seus seguidores, entre os quais o mais badalado foi Jung, como já assinalou Lacan (1965/1993b, p. 836). De fato, em suas elaborações iniciais que logo rejeitou teoricamente, Freud habilitou a interpretação básica para dotar ao sujeito da psicanálise de profundidades inconscientes objetiváveis; já o 
efeito de seus dizeres no pensamento psicanalítico estadunidense abriu a possibilidade de definir o inconsciente como um consciente anômalo e submerso.

O "cientificismo" de Lacan serviu-se de sua análise da questão do signo, com de Saussure e Levi-Strauss como interlocutores, para inserir na sua leitura de Freud a afirmação de que o "inconsciente está estruturado como uma linguagem". Foi daí que decorreu, até a década de 1970 (no "primero classicismo lacaniano" de Milner, 1995/ 1996, pp. 81-121) uma particular e intensa afetação entre a psicanálise e a lingüística, que ficou menos evidente em anos posteriores (no "segundo classicismo lacaniano" de Milner, 1995/1996, pp. 81121), nos quais preponderaram os modelos topológico-matemáticos. Quaisquer que sejam as posições que alentemos perante a proposta de Milner, no sentido de aceitá-la ou de rejeitá-la, parece evidente que a proximidade do pensamento de Lacan com o "saber" oriundo da lingüística ou da matemática forma evidentemente parte de seu percurso de pensamento.

Há, portanto, e na medida em que a psicanálise não é uma prática sem teoria, uma relação entre a psicanálise e a ciência. Isto não é equivalente à afirmação "a psicanálise é uma ciência", discussão que muito pouco tem a ver com a nossa. Também é necessário distinguir ciência, como a dimensão referida aos assuntos do conhecimento, o saber, a verdade e o Real, e "ciências" como práticas sociais e históricas concretas. A identificação de uns assuntos e dos outros produz alguns desencaminhamentos, notadamente a redução da ciência à tecnociência, deslize que observamos como muito frequente em textos da corrente chamada de "clínica do social", como Lebrun (2001/2004). Como sabemos pelo próprio "doutrinal da ciência" lacaniano, explicitamente apresentado em Lacan (1993b) e pesquisado atentamente por Milner (1991/1997 e 1995/1996), a ciência não é um fenômeno exclusivo do imaginário, uma mera reprodução ad libitum de representações ou uma simples tecnologia que se aplica automaticamente, mas o bordeado simbólico de um Real que "insiste em não se inscrever", instaurando o saber como falta e desejo. Nas dobras dos modelos epistemológicos de Kojève, Koyré e Popper, Lacan constrói uma epistemologia que põe um ponto de fusão entre o saber da ciência e o saber do sujeito e da psicanálise. O predomínio das tecnociências na sociedade e na academia contemporânea, embora seja um problema interessante e preocupante, não deve ser apresentado como a marca de consti- 
tuição de uma epistemologia lacaniana.

Com efeito, se bem para Lacan as ciências históricas contemporâneas podem constituir uma teia imaginária, existe para ele um registro na "borromeidade" no qual a ciência está incluída no simbólico, na medida em que é na cadeia significante que sua dimensão heurística permeia um saber não sabido, o que faz da ciência um espaço do desejo. A questão se coloca, então, na relação do sujeito com o movimento ou funcionamento das representações na ciência:

Todo lo que hay allí de experiencia algo ilustrada indica que el sujeto depende de esta cadena articulada que representa la adquisición científica. El sujeto tiene que ocupar su lugar, situarse como puede en las consecuencias de esta cadena. Necesita revisar en cada momento todas las pequeñas representaciones intuitivas que se había hecho y que se desplazan al mundo e incluso a las categorías supuestamente intuitivas. Todo el tiempo hace que se recomience, con el objeto incluso de alojarse, por poco que no haya quedado fuera de este sistema (Lacan 1967/ 2006c, pp. 104-5).

A flutuação entre a estabilidade e a instabilidade das representações é o espaço da ciência, é por isso que o sujeito da ciência é o mesmo que o sujeito da psicanálise ("El sujeto sobre el que operamos en psicoanálisis no puede ser sino el sujeto de la ciencia”, Lacan, 1965/1993b, p. 837).

Outro tanto deveríamos dizer da relação entre a psicanálise e a teoria do ensino, que, como já foi sublinha- 
do aqui, atraiu o interesse de Lacan. Tanto para a tradição da teoria do ensino como para a teoria lacaniana pode-se afirmar que existe ensino porque existe ciência, definida como na sua etimologia latina primária: sciens, tis, participio activo de scire, "saber". As nossas traduções de Freud, Begusste $=$ consciência $\mathrm{e}$ Unbegusste $=i n$ consciente, servem-se deste valor léxico latino. Se a questão do saber é a que faz possível uma relação entre a teoria do ensino e a teoria psicanalítica, não devemos produzir uma redução, porque isto suporia uma sorte de "interdisciplinariedade" que, como sabemos, é a negação da epistemologia lacaniana. Com efeito, a noção de saber de que se trata na particular estrutura teórica da psicanálise não é radicalmente coextensiva ao conceito de saber próprio da ciência e do ensino. Mas, como vimos, há intersecções, já que a própria epistemologia lacaniana permite.

\section{Desejo na universidade?}

A pergunta do subtítulo é muito "escandalosa", no sentido próprio deste termo, que indica a propriedade de "provocar embaraço ou agredir com indecorosidade". O embaraçoso ou indecoroso, evidenciando outros sentidos conotados, é relacionar conhecimento com desejo e com ensino. Sem dúvidas, o discurso universitário contemporâneo se articula 
nas antípodas do desejo, na aspiração dos "encaixamentos" do conhecimento recebido, na sua correta, controlável, eficiente e avaliável "transmissão". Por isso um termo como "desejo" costuma a se relacionar com a "motivação" dos alunos, no marco de referência das teorias psicopedagógicas, e não com a natureza intrínseca do saber, que supõe-se que ela pratique e abrigue.

Ao longo deste texto almejamos uma afetação teórica entre a teoria do ensino universitário e a teoria psicanalítica, com o intuito de que a segunda pode produzir efeitos na primeira. Como vimos, esses efeitos implicam reconhecer que, se o ensino universitário se define no seu núcleo central em relação à chamada "produção de conhecimento" (definição clássica de ensino superior), a questão do saber do ensinante e do científico não devem ser tratadas em separado, porque as duas estão vinculadas a uma sujeição: aquela que a psicanálise lacaniana matemiza com o termo "desejo".

Que a Universidade não seja em nossos tempos um âmbito para o cultivo da ciência e do pensamento, e que, portanto não haja nela espaço para o "enigma" e o "desejo", substituídos pelas certezas e os controles psicotécnicos e didáticos, é uma outra questão.

FURTHER ON "FITTINGS": THE NOTION OF UNIVERSITY TEACHING AFFECTED BY PSYCHOANALYTICAL THEORY

\begin{abstract}
The paper aims to make a contribution to the theoretical traces of universitary teaching, taking into account the effects that psychoanalytical theory provides. Especially, the notion of "teacher's desire", as established by Lacan, is related to the basic nature of this kind of teacbing. The paper intends to show the importance of "lacking knowledge" in the discussion about the universitary tradition of teaching, and its differences with the tradition of teaching theory in modern education. Otherwise, a discussion about the status of the relationship science-teaching is included, mainly in the framework of psychoanalytical "cientificism".
\end{abstract}

Index terms: university teaching; psychoanalytical theory; teacher's desire.

MÁS ALLÁ DE LOS “ENCAJADURAS”: LA NOCIÓN DE ENSEÑ ANZA UNIVERSITARIA AFECTADA POR LA TEORÍA PSICOANALÍTICA

\title{
RESUMEN
}

El texto intenta hacer una contribución a los rasgos teoréticos de la enseñanza universitaria, tomando en consideración los efectos que la teoria psicoanalitica permite. Especialmente, se relaciona la noción de "deseo del enseñante", tal como la estableció Lacan, con la naturaleza básica de este tipo de enseñanza. El trabajo pretende mostrar la importancia del "saber en 
falta" en la discusión acerca de la tradición universitaria de enseñanza y sus diferencias con la tradición de la teoría de la enseñanza en la educación moderna. Además, se incluye una discusión acerca del estatus de la relación ciencia-enseñanza, principalmente en el marco de referencia del "cientificismo" psicoanalítico.

Palavras clave: enseñanza universitaria; teoria psicoanalitica; deseo del enseñante.

\section{REFERÊNCIAS}

Agustín de Hipona (1873). De Magistro. In CEuvres Complètes de Saint Augustin Évêque d'Hippone (Vol. 3, pp. 254-291) Paris: Librairie de Louis Vivès (Trabalho original publicado em 359)

Allouch, J. (1994). Freud y después Lacan. Buenos Aires: Edelp. (Trabalho original publicado em 1993)

Behares, L. E. (2007). Enseñar en cuerpo y alma: la teoría de la enseñanza y el saber en la pulsión. ETD - Educação Temática Digital, 8 (número especial), 1-21.

Behares, L. E. (2008). Para una teoría de la enseñanza a la altura del sujeto: la articulación aprés-coup. In N. V. Leite \& F. Trócoli (Orgs.), Um retorno a Freud. Campinas, SP: Mercado de Letras.

Behares, L. E. (2010). Saber y terror de la enseñanza. Montevideo: Psicolibros-Waslala.

Behares, L. E. (2011). Enseñanza y producción de conocimiento. La noción de enseñanza en las politicas universitarias uruguayas. Montevideo: Comisión Sectorial de Investigación Científica/Universidad de la República.

Chevallard, Y. (1998). La transposición didáctica: del saber sabio al saber enseñado. Buenos Aires: Aique. (Trabalho original publicado em 1985)

Lajonquière, L. (1999). Infancia e ilusión (psico)pedagógica: escritos de psicoanálisis y educación. Buenos Aires: Nueva Visión.

Fernández, A. M. (2006). "Lo niño” y el psicoanálisis ¿posibilidad o imposibilidad? 
ETD - Educacão Temática Digital, 8 (número especial), 20-48.

Freud, S. (2003a). Tres ensayos de teoría sexual. In S. Freud, Obras completas, (J. L. Etcheverry, trad., Vol. 7, pp. 109-222). Buenos Aires: Amorrortu. (Trabalho original publicado em 1905)

Freud, S. (2003b). Pulsiones y destinos de pulsión. In S. Freud, Obras completas, (J. L. Etcheverry, trad., Vol. 14, pp. 105-139). Buenos Aires: Amorrortu. (Trabalho original publicado em 1915)

Freud, S. (2003c). Sobre las teorías sexuales infantiles. In S. Freud, Obras completas, (J. L. Etcheverry, trad., Vol. 9, pp. 183-200). Buenos Aires: Amorrortu. (Trabalho original publicado em 1908)

Freud, S. (2003d). La represión. In S. Freud, Obras completas, (J. L. Etcheverry, trad., Vol. 14, pp. 135-152). Buenos Aires: Amorrortu. (Trabalho original publicado em 1915)

Freud, S. (2003e). ¿Debe enseñarse el psicoanálisis en la universidad? In S. Freud, Obras completas, (J. L. Etcheverry, trad., Vol. 22, pp. 165-171). Buenos Aires: Amorrortu. (Trabalho original publicado em 1918)

Freud, S. (2003f). Prólogo a August Aichhorn, Verwahrloste Jugend. In S. Freud, Obras completas,(J. L. Etcheverry, trad., Vol. 19, pp. 296-298). Buenos Aires: Amorrortu. (Trabalho original publicado em 1925)

Freud, S. (2004a). Análisis terminable e interminable. In S. Freud, Obras completas, J. L. Etcheverry, trad., Vol. 23, pp. 212254). Buenos Aires: Amorrortu. (Trabalho original publicado em 1937)

Freud, S. (2004b). ¿Pueden los legos ejercer el análisis? Diálogos con un juez imparcial. In S. Freud, Obras completas, (J. L. Etcheverry, trad., Vol. 20, pp. 165-244). Buenos Aires: Amorrortu. (Trabalho original publicado em 1926)

Jones, E. (2003). Vida y obra de Sigmund Freud. (Edición abreviada a cargo de L. Trilling y S. Marcus). Barcelona, Espanha: Ana- grama. (Trabalho original publicado em 1961)

Kachinovsky, A. (2010). Territorios sin diván. In A. Kachinovsky (Coord.). Memorias de la clínica (pp. 239-251). Montevideo: Universidad de la República-Facultad de Psicología.

Lacan, J. (1961-1962). La identificación (inédito/versión integral).

Lacan, J.(1992). El seminario, libro 17: el reverso del psicoanálisis, 1969-1970. (N. González, trad.). Paidós: Buenos Aires.

Lacan, J. (1993a). El seminário, libro 1: los escritos técnicos de Freud, 1953-1954. (R. Cevasco \& V. M. Pascual, trads.). Buenos Aires: Paidós.

Lacan, J. (1993b). La ciencia y la verdad. In J. Lacan, Escritos 2. (T. Segovia, trad., pp. 834-856). México: Siglo XXI Editores.

Lacan, J. (2003a). El seminário, libro 8: la transferencia, 1960-1961. (E. Berenguer, trad.). Paidós: Buenos Aires.

Lacan, J. (2003b). Alocução sobre o ensino. In Outros escritos. (V. Ribeiro, trad. pp. 302310). Rio de Janeiro: Jorge Zahar.

Lacan, J. (2006a). Lugar, origen y fin de mi enseñanza. (N. González, trad., pp. 11-76). In J. Lacan, Mi enseñanza. Buenos Aires: Paidós.

Lacan, J. (2006b). Entonces, habrán escuchado a Lacan. (N. González, trad., pp. 117-143). In J. Lacan, Mi enseñanza. Buenos Aires: Paidós.

Lacan, J. (2006c). Mi enseñanza, su naturaleza y sus fines. In J. Lacan, Mi enseñanza. (N. González, trad. pp. 77-115). Buenos Aires: Paidós.

Lacan, J. (2006d). El seminário, libro 10: la angustia, 1962-1963. (R. Cevasco \& V. M. Pascual, trads.). Buenos Aires: Paidós.

Lacan, J. (2008). El seminário, libro 16: de un Otro al outro, 1968-1969. (E. Berenguer \& M. Bassols, trads.). Paidós: Buenos Aires. Lebrun, J-P. (2004). Um mundo sem limite: ensaio para uma clinica psicanalítica do social. Rio de Janeiro: Companhia de Freud. (Trabalho original publicado em 2001) 


\section{Dossiê}

Milner, J-C. (1996). La obra clara: Lacan, la ciencia, la filosofía. Buenos Aires: BordesManantial. (Trabalho original publicado em 1995)

Milner, J-C. (1997). Lacan y la ciencia moderna. In Biblioteca del Colegio Internacional de Filosofía, Lacan con los Filósofos (E. Cazenave-Tapie, trad., pp. 307323). México: Siglo XXI. (Trabalho original publicado em 1991)

Pommier, G. (2005). Qué es lo "Real": ensayo psicoanalítico. (N. Prado, trad.) Buenos Aires: Nueva Visión. (Trabalho original publicado em 2004)

Rancière, J. (2003). El maestro ignorante. Barcelona: Laertes (Trabalho original publicado em 1995).

Voltolini, R. (2010). O ensino universitário na época do declínio dos saberes. Didáskomai. Revista de Investigaciones sobre la Enseñan₹a, 1, 25-40. 